\section{Case Reports in Neurology}

Case Rep Neurol 2020;12:291-298

DOI: 10.1159/000508994

Published online: September 17, 2020

(C) 2020 The Author(s)

Published by S. Karger AG, Basel

www.karger.com/crn

This article is licensed under the Creative Commons Attribution-NonCommercial 4.0 International License (CC BY-NC) (http://www.karger.com/Services/OpenAccessLicense). Usage and distribution for commercial purposes requires written permission.

\title{
Monomelic Amyotrophy (Hirayama Disease): A Rare Case Report and Literature Review
}

\author{
Jasem Y. Al-Hashel ${ }^{a, b} \quad$ Ehab A. Abdelnabi ${ }^{c} \quad$ Ismail Ibrahim Ismail ${ }^{a}$ \\ ${ }^{a}$ Department of Neurology, Ibn Sina Hospital, Safat, Kuwait; ${ }^{b}$ Department of \\ Medicine, Health Sciences Centre, Faculty of Medicine, Kuwait University, Jabriya, Kuwait; \\ 'Department of Radiology, Ibn Sina Hospital, Safat, Kuwait
}

\section{Keywords}

Hirayama's disease · Monomelic amyotrophy · Juvenile non-progressive amyotrophy

\begin{abstract}
Hirayama disease is a rare neurological entity that is characterized by initial progressive muscular wasting and weakness of the distal upper limb in young men, followed by a spontaneous arrest within several years. The disease is believed to be a result of forward displacement of the cervical dural sac and spinal cord induced by neck flexion. It is commonly seen in Asia and rarely encountered in the Middle East countries. We report a rare case of a 20-year-old Kuwaiti patient presenting with a 10-month duration of gradual left upper limb weakness and wasting. We describe his electrophysiological and radiological findings that confirmed the diagnosis, and conducted a literature review. Hirayama disease is rarely encountered in clinical settings and should be suspected in male patients presenting with unilateral or asymmetrical bilateral lower motor weakness of hands and forearms. It is a benign entity, and cervical collar is usually the only treatment needed in most cases.

(C) 2020 The Author(s)

Published by S. Karger AG, Basel
\end{abstract}

\section{Introduction}

Hirayama disease, is a rare entity characterized by unilateral or asymmetrical bilateral focal weakness and wasting of muscles innervated by $\mathrm{C} 7, \mathrm{C} 8$, and $\mathrm{T} 1$. It shows a gradual onset 


\section{Case Reports in Neurology}

Case Rep Neurol 2020;12:291-298

DOI: 10.1159/000508994

2020 The Author(s). Published by S. Karger AG, Basel www.karger.com/crn

Al-Hashel et al.: Monomelic Amyotrophy (Hirayama Disease)

and benign course that commonly affects young males (male:female ratio of 20:1) between the ages of 15 and 25 years [1]. It was first described by Hirayama et al. [2] in 1959 as "juvenile muscular atrophy of unilateral upper extremity" and in 1984, Gourie-Devi et al. [3] coined the term "monomelic amyotrophy" [3].

The incidence of Hirayama disease is low, and it is rarely encountered in the clinical settings. Most case reports in the literature are from Asian countries and it is rarely encountered in the Middle East or Arab countries. We report "Hirayama disease" in a 20-year-old male who presented with gradual left upper limb weakness and wasting, with "oblique atrophy" and "reversed split hand syndrome," that was confirmed by electrophysiological and radiological studies.

\section{Case Presentation}

A 20 year-old male with no relevant medical history presented with 10 months' duration of weakness and wasting of the hand and forearm on the left side. His weakness and atrophy started initially in the small muscles of the left hand and gradually progressed to involve the left forearm muscles. There were no other muscles affected in both upper and lower limbs, and he did not have any pain, loss of sensation, ptosis, diplopia, dysphagia, cramps, or fasciculations. He had no history of trauma, fever, exposure to toxins or heavy metals, history of poliovirus infection, and his family history was negative for similar conditions.

Neurological examination showed an alert, conscious, and oriented man with normal speech and higher mental functions. His cranial nerves were normal. Motor examination showed atrophy and weakness (G4/5) of the thenar, hypothenar, interosseous, and forearm muscles with sparing of the brachioradialis muscle on the left side (Fig. 1). Deep tendon reflexes were 2+ (normal) allover. Superficial and deep sensory examination was normal. Coordination and gait were normal. He had no fasciculations, tremors, involuntary movements or abnormal sweating.

Routine laboratory investigations (complete blood count, renal function tests, liver function tests, serum electrolytes, thyroid function tests, erythrocyte sedimentation rate, and creatine phosphokinase) were within normal limits. Vasculitic workup (ANA, anti-dsDNA, RF, ENA, and CRP) was negative. Plain cervical X-ray showed only loss of cervical lordosis.

Nerve conduction study showed a low compound muscle action potential (CMAP) amplitude in the abductor digiti minimi while preserved in abductor pollicis brevis during proximal and distal stimulation of both Ulnar and Median nerves, respectively. Electromyogram (EMG) showed evidence of denervation in C7, C8 distribution with sparing of the brachioradialis muscle, and chronic neurogenic changes in thoracic paraspinals on the left side. There was no affection of the lower limb muscles.

Magnetic resonance imaging (MRI) of the cervical spine was performed using a 3T magnet in neutral position and showed straightening of the neck with atrophy of the cord opposite C5-6. With neck flexion, there was anterior displacement of the posterior dura and enlargement of the posterior epidural space with increase in the laminodural distance (from 1.4 to $6.1 \mathrm{~mm}$ ) (Fig. 2, 3).

The patient received the diagnosis of "Hirayama disease" based on his clinical, electrophysiological, and radiological characteristics. He was treated with cervical collar in order to prevent neck flexion, in addition to physiotherapy. He had a stable course with no progression over a 12-month follow-up period. 


\section{Case Reports in Neurology}

Case Rep Neurol 2020;12:291-298

DOI: $10.1159 / 000508994$

(c) 2020 The Author(s). Published by S. Karger AG, Basel www.karger.com/crn

Al-Hashel et al.: Monomelic Amyotrophy (Hirayama Disease)

\section{Discussion}

Hirayama disease is a benign form of focal amyotrophy that affects C7, C8, and T1 segmental myotomes with sparing of the brachioradialis, giving the characteristic appearance of "oblique amyotrophy," and sparing the proximal muscles of the upper limb innervated by C56 myotomes. It manifests with gradual unilateral or asymmetric bilateral muscle weakness and atrophy in young males and is usually self-limited. It can be associated with autonomic dysfunction in distal upper limbs in the form of exaggeration of weakness on exposure to cold (cold paresis), cold skin, excessive sweating, and hair loss over the dorsum of the hands, and bilateral minipolymyoclonus. Approximately $70 \%$ of the patients experience disease progression within 3 years, and approximately 95\% stabilize 5 years after disease onset [4].

It differs from classical types of motor neuron diseases because of its self-limited nature and the pathological findings of chronic microcirculatory changes in the anterior horns of the lower cervical cord. The pathogenesis of Hirayama disease still remains obscure. The first pathological study was published by Hirayama et al. [5] in 1987 on a patient after 23 years of disease onset and showed necrosis and degeneration of various degrees of large and small nerve cells with mild gliosis only in the anterior horns of the spinal cord at C5 to T1, particularly marked at C7 and C8. They suggested circulatory insufficiency in the lower cervical cord as the leading cause. However, current neuroradiological techniques are able to show forward displacement of the posterior wall of the lower cervical dural canal when the neck is flexed, causing marked and often asymmetric flattening of the lower cervical cord, which is presumed to be the primary pathogenetic mechanism of Hirayama disease $[6,7]$.

In "Hirayama disease" patients, there is imbalance in growth of the vertebrae and the dura mater leading to a "tight dural canal" and "overstretched cord," which cannot compensate for the increased length of the posterior wall during flexion. This causes an anterior shifting of the posterior dural wall, with consequent compression of the cord. This compression from repeated or sustained flexion of the neck may cause chronic microcirculatory disturbances in the anterior portion of the spinal cord may produce necrosis of the anterior horns, which are most vulnerable to ischemia [8].

Around 1,500 patients were reported in the literature, and these cases were common in Asian countries with the largest studies from Japan (333 cases) [9], India (279 cases) [3], and China (179 cases) [10].

The contribution of family history was rarely observed; however, some susceptibility genes such as KIAA1377 and C5ORF42 were proposed [11]. It is believed that certain environmental factors, ethnic background, or cultural and behavioral habits might be involved in the susceptibility to the disease.

Clinical diagnosis is confirmed by electrophysiological and radiological studies. EMG findings are indicative of chronic denervation noted in the $\mathrm{C} 7, \mathrm{C} 8$, and $\mathrm{T} 1$ innervated muscles, with or without acute denervation potentials (fasciculations, positive sharp waves and fibrillations potentials). "Reverse split hand syndrome," which is characterized by decreased/absent CMAP amplitude in the abductor digiti minimi while preserved in the abductor pollicis brevis, is usually seen in nerve conduction study. It differentiates "Hirayama disease" from ALS which shows classical "Split hand syndrome" [12,13].

In about $25-50 \%$ of the cases, non-atrophic asymptomatic muscles (i.e., triceps brachii, brachioradialis, biceps brachii, and deltoid muscles) on the affected side sometimes can show denervation. Furthermore, the mean ulnar/median CMAP amplitude ratio is significantly lower in "Hirayama disease" while abnormally higher in ALS when compared with normal subjects. During the progressive phase of the disease, neck flexion could lead to a decrease of 


\section{Case Reports in Neurology}

Case Rep Neurol 2020;12:291-298

DOI: 10.1159/000508994

2020 The Author(s). Published by S. Karger AG, Basel www.karger.com/crn

Al-Hashel et al.: Monomelic Amyotrophy (Hirayama Disease)

F-wave persistency; and in patients with severe wasting, the F-wave may become absent [14, 15].

Routine MRI in neutral position is often reported as normal, but it can also show lower cervical cord atrophy or abnormal cervical curvature (straight or kyphotic). However, the classical MRI findings of cervical spine in neck flexion include: forward displacement of the posterior wall, loss of the posterior dural sac attachment with adjacent lamina, and a wellenhanced crescent-shaped mass in the posterior epidural space of the lower cervical canal. This is thought to represent congestion of the posterior internal vertebral venous plexus as it disappears on neutral neck position [7]. The increase in the laminodural space and the presence of cervical cord flattening during flexion are essential for diagnosis as described by Boruah et al. [16] in 45 patients with clinically definite "Hirayama disease." He found that the laminodural space at maximum forward shifting of the posterior dural sac ranged from 3 to $9.8 \mathrm{~mm}$, with a mean distance of $5.99 \mathrm{~mm}$.

Vitale et al. [17] suggested an MRI protocol including: sagittal T1-weighted and T2weighted sequences and axial T2 or T2*-weighted sequence in neutral position; sagittal T2weighted sequences and axial T2 or T2*-weighted sequence in a neck-flexion of 25-35 degrees in addition to sagittal T1-weighted sequences in neck-flexion before and after gadolinium intravenous administration. Snake-eyes appearance, a radiological finding described as a symmetrical bilateral small high-signal-intensity lesion on axial T2-weighted MRI, appears during the late stage of "Hirayama disease" and is proposed as an indicator of irreversible damage and poor prognosis [18].

According to a nationwide study in Japan by Tashiro et al. [4], the following criteria are important for diagnosis: (1) distal predominant muscle weakness and atrophy in the forearm and hand; (2) involvement of the unilateral upper extremity in most cases; (3) onset between the ages of 10 to early 20s; (4) insidious onset with gradual progression for the first several years, followed by stabilization; (5) no lower extremity involvement; (6) no sensory disturbance or tendon reflex abnormalities; and (7) exclusion of other diseases. All these criteria were fulfilled in our patient.

Several conditions can be considered in the differential diagnosis of "Hirayama disease" including: amyotrophic lateral sclerosis, spinal muscle atrophy, C8-T1 radiculopathy, compressive myelopathy, cervical spondylotic myelopathy, syringomyelia, post-polio syndrome, multifocal motor neuropathy, and toxic neuropathy [19].

As "Hirayama disease" is considered a self-limited disease and often stops progressing after 1-5 years of onset, the mainstay of treatment consists of preventing neck flexion using a cervical collar to halt further progression. Its application at an early stage of the disease for $3-$ 4 years has been advocated with good response [20]. EMG can be used as an indicator to start and to stop cervical collar therapy depending on changes of latency and amplitude of motor evoked potentials and persistence of F wave on neck flexion [21]. Good prognosis is seen in patients with shorter duration of illness and no or mild cord atrophy in neutral neck position [20].

Surgical intervention has been proposed by some authors; however, patients with "Hirayama disease" usually stabilize with conservative treatment, and surgery should be limited to severe cases that have progressed quickly [22]. Cervical spinal decompression with fusion and duraplasty showed good results in selected patients because it gives a permanent stable fixation with a shorter period of immobilization [23]. Controlled clinical trials are needed to establish firm guidelines for these therapeutic options.

In conclusion, we presented a rare case report of "Hirayama disease" that is rarely encountered in clinical practice in Arab countries. It should be suspected in male patients 


\section{Case Reports in Neurology}

\begin{tabular}{l|l}
\hline Case Rep Neurol 2020;12:291-298 \\
\hline DOI: 10.1159/000508994 & $\begin{array}{l}\text { @ 2020 The Author(s). Published by S. Karger AG, Basel } \\
\text { www.karger.com/crn }\end{array}$ \\
\hline
\end{tabular}

Al-Hashel et al.: Monomelic Amyotrophy (Hirayama Disease)

presenting with unilateral or asymmetrical bilateral lower motor weakness of hands and forearms. It is a benign entity and no treatment other than cervical collar is usually needed in most cases. EMG can be used as an indicator to start and to stop cervical collar therapy.

\section{Acknowledgement}

We would like to thank Dr. Adnan J. Khuraibet for his comprehensive electrophysiological study. We would also like to thank the patient for his cooperation.

\section{Statement of Ethics}

The authors have no ethical conflicts to disclose. The authors confirm obtaining written consent from the patient for publication of the manuscript (including images, case history, and data).

\section{Conflict of Interest Statement}

The authors have no conflicts of interest to declare.

\section{Funding Sources}

The authors did not receive any funding support.

\section{Author Contributions}

J.Y.A.-H. contributed to drafting the manuscript and patient management. E.A.A. contributed to radiological imaging and reporting. I.I.I. drafted the manuscript, helped in patient management, and performed the literature review. All authors approved the final version of the manuscript.

\section{References}

1 Huang YC, Ro LS, Chang HS, Chen CM, Wu YR, Lee JD, et al. A clinical study of Hirayama disease in Taiwan. Muscle Nerve. 2008 May;37(5):576-82.

2 Hirayama K, Toyokura Y, Tsubaki T. Juvenile muscular atrophy of unilateral upper extremity: a new clinical entity [in Japanese]. Psychiatr Neurol Jpn. 1959;61:2190-8.

3 Gourie-Devi M, Suresh TG, Shankar SK. Monomelic amyotrophy. Arch Neurol. 1984 Apr;41(4):388-94.

4 Tashiro K, Kikuchi S, Itoyama Y, Tokumaru Y, Sobue G, Mukai E, et al. Nationwide survey of juvenile muscular atrophy of distal upper extremity (Hirayama disease) in Japan. Amyotroph Lateral Scler. 2006 Mar;7(1):38-45.

5 Hirayama K, Tomonaga M, Kitano K, Yamada T, Kojima S, Arai K. Focal cervical poliopathy causing juvenile muscular atrophy of distal upper extremity: a pathological study. J Neurol Neurosurg Psychiatry. 1987 Mar;50(3):285-90.

6 Kikuchi S, Tashiro K, Kitagawa M, Iwasaki Y, Abe H. [A mechanism of juvenile muscular atrophy localized in the hand and forearm (Hirayama's disease)-flexion myelopathy with tight dural canal in flexion] [in Japanese]. Rinsho Shinkeigaku. 1987 Apr;27(4):412-9. 


\section{Case Reports in Neurology}

\begin{tabular}{l|l}
\hline Case Rep Neurol 2020;12:291-298 \\
\hline DOI: 10.1159/000508994 & $\begin{array}{l}\text { ○ 2020 The Author(s). Published by S. Karger AG, Basel } \\
\text { www.karger.com/crn }\end{array}$ \\
\hline
\end{tabular}

Al-Hashel et al.: Monomelic Amyotrophy (Hirayama Disease)

7 Raval M, Kumari R, Dung AA, Guglani B, Gupta N, Gupta R. MRI findings in Hirayama disease. Indian J Radiol Imaging. 2010 Nov;20(4):245-9.

8 Narayana Gowda BS, Mohan Kumar J, Basim PK. Hirayama's Disease - A Rare Case Report with Review of Literature. J Orthop Case Rep. 2013 Jul-Sep;3(3):11-4.

9 Hirayama K. [Juvenile muscular atrophy of unilateral upper extremity (Hirayama disease) - half-century progress and establishment since its discovery]. Brain Nerve. 2008 Jan;60(1):17-29.

10 Zhou B, Chen L, Fan D, Zhou D. Clinical features of Hirayama disease in mainland China. Amyotroph Lateral Scler. 2010;11(1-2):133-9.

11 Lim YM, Koh I, Park YM, Kim JJ, Kim DS, Kim HJ, et al. Exome sequencing identifies KIAA1377 and C5orf42 as susceptibility genes for monomelic amyotrophy. Neuromuscul Disord. 2012 May;22(5):394-400.

12 Guo XM, Qin XY, Huang C. Neuroelectrophysiological characteristics of Hirayama disease: report of 14 cases. Chin Med J (Engl). 2012 Jul;125(14):2440-3.

13 Singh RJ, Preethish-Kumar V, Polavarapu K, Vengalil S, Prasad C, Nalini A. Reverse split hand syndrome: dissociated intrinsic hand muscle atrophy pattern in Hirayama disease/brachial monomelic amyotrophy. Amyotroph Lateral Scler Frontotemporal Degener. 2016;30:1-7.

14 Hassan KM, Sahni H. Nosology of juvenile muscular atrophy of distal upper extremity: from monomelic amyotrophy to Hirayama disease-Indian perspective. BioMed Res Int. 2013;2013:478516.

15 Jin X, Jiang JY, Lu FZ, Xia XL, Wang LX, Zheng CJ. Electrophysiological differences between Hirayama disease, amyotrophic lateral sclerosis and cervical spondylotic amyotrophy. BMC Musculoskelet Disord. 2014 Oct;15(1):349.

16 Boruah DK, Prakash A, Gogoi BB, Yadav RR, Dhingani DD, Sarma B. The Importance of Flexion MRI in Hirayama Disease with Special Reference to Laminodural Space Measurements. AJNR Am J Neuroradiol. 2018 May;39(5):974-80.

17 Vitale V, Caranci F, Pisciotta C, Manganelli F, Briganti F, Santoro L, et al. Hirayama's disease: an Italian single center experience and review of the literature. Quant Imaging Med Surg. 2016 Aug;6(4):364-73.

18 Xu H, Shao M, Zhang F, Nie C, Wang H, Zhu W, et al. Snake-eyes appearance on MRI occurs during the late stage of Hirayama disease and indicates poor prognosis. BioMed Res Int. 2019 Jan;2019:9830243.

19 Huh JP, Sung DH, Jo JM, Yoo JS, Kim BJ. Clinical characteristics, electrodiagnostic, and imaging findings of atypical forms of motor neuron disease. J Korean Acad Rehabil Med. 2010;34:701-9.

20 Tokumaru Y, Hirayama K. [A cervical collar therapy for non-progressive juvenile spinal muscular atrophy of the distal upper limb (Hirayama's disease)]. Rinsho Shinkeigaku. 1992 Oct;32(10):1102-6.

21 Chiba S, Yonekura K, Nonaka M, Imai T, Matumoto H, Wada T. Advanced Hirayama disease with successful improvement of activities of daily living by operative reconstruction. Intern Med. 2004 Jan;43(1):79-81.

22 Agundez M, Rouco I, Barcena J, Mateos B, Barredo J, Zarranz JJ. Hirayama disease: is surgery an option? Neurologia. 2015 Oct;30(8):502-9.

23 Imamura H, Matsumoto S, Hayase M, Oda Y, Kikuchi H, Takano M. [A case of Hirayama's disease successfully treated by anterior cervical decompression and fusion]. No To Shinkei. 2001 Nov;53(11):1033-8.

ORCID iD: https://orcid.org/0000-0002-9788-7044 
Case Reports in

Neurology
Case Rep Neurol 2020;12:291-298

DOI: $10.1159 / 000508994$

(c) www.karger.com/crn

Al-Hashel et al.: Monomelic Amyotrophy (Hirayama Disease)
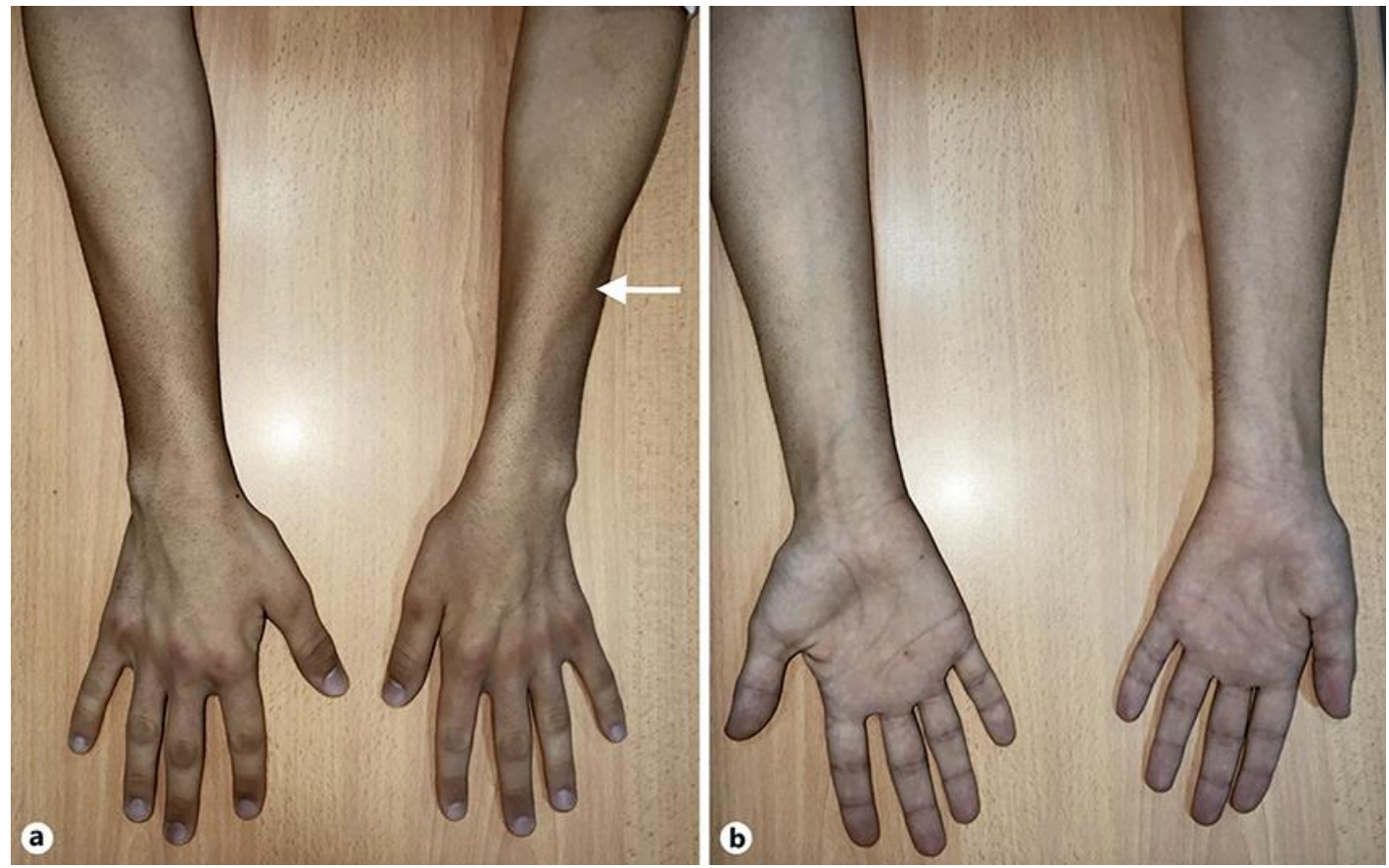

Fig. 1. A 20-year-old male with Hirayama disease showing atrophy of the small muscles of the hand and forearm on the left side. a In pronation showing sparing of the brachioradialis muscle (oblique atrophy, arrow). $\mathbf{b}$ In supination.
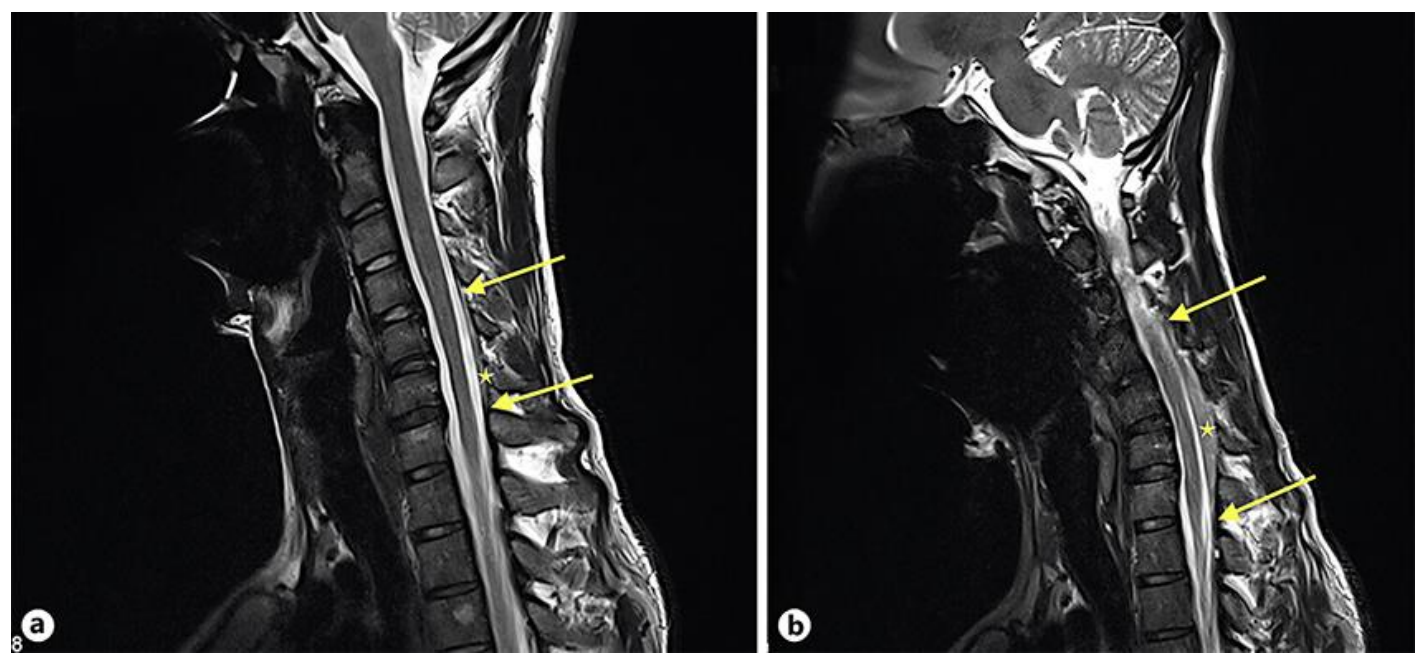

Fig. 2. MRI cervical spine with sagittal T2-weighted spin echo images. a In neutral position, showing cervical cord straightening and cord thinning opposite the C5-6 level that may reflect cord atrophy. $\mathbf{b}$ In flexion, showing anterior displacement of the posterior dura, enlargement of the posterior epidural space with increase in the "laminodural distance" from to 1.4 to $6.1 \mathrm{~mm}$ (asterisks) as well as increase in length (arrows). 
Case Reports in Neurology
Case Rep Neurol 2020;12:291-298 DOI: $10.1159 / 000508994$
(C) 2020 The Author(s). Published by S. Karger AG, Basel www.karger.com/crn

Al-Hashel et al.: Monomelic Amyotrophy (Hirayama Disease)
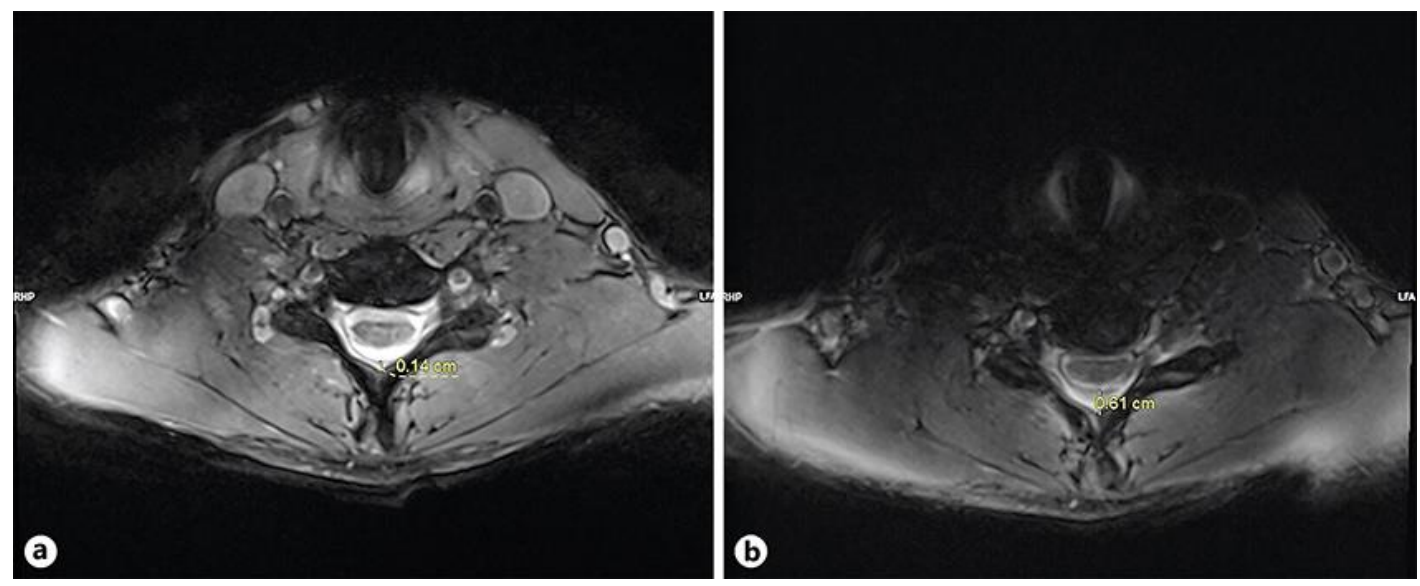

Fig. 3. MRI cervical spine with axial T2-weighted gradient echo images in (a) neutral position and (b) in flexion. It confirms the anterior displacement of the posterior dura during flexion, resulting in an increase of the corresponding laminodural distance. 